\title{
A novel anti-tumor protein extracted from Meretrix meretrix Linnaeus induces cell death by increasing cell permeability and inhibiting tubulin polymerization
}

\author{
XUANXUAN NING ${ }^{1,2}$, JIANMIN ZHAO ${ }^{1}$, YUYAN ZHANG ${ }^{1}$, SUBING CAO $^{1}$, \\ MING LIU ${ }^{1}$, PEIXUE LING ${ }^{3}$ and XIUKUN LIN ${ }^{1}$ \\ ${ }^{1}$ Institute of Oceanology, Chinese Academy of Sciences, Qingdao 266071; \\ ${ }^{2}$ Yantai Oceanic Environmental Monitoring Central Station of SOA, Yantai 264006; \\ ${ }^{3}$ Institute of Biopharmaceuticals of Shandong Province, Jinan 250012, P.R. China
}

Received March 23, 2009; Accepted June 2, 2009

DOI: 10.3892/ijo_00000393

\begin{abstract}
Discovery and development of new pharmaceuticals from marine organisms are attracting increasing interest. Several agents derived from marine organisms are under preclinical and clinical evaluation as potential anticancer drugs. We extracted and purified a novel anti-tumor protein from the coelomic fluid of Meretrix meretrix Linnaeus by ammonium sulphate fractionation, ion exchange and hydrophobic interaction chromatography. The molecular weight of the highly purified protein, designated MML, was $40 \mathrm{kDa}$ as determined by SDS-PAGE analysis. MML exhibited significant cytotoxicity to several cancer cell types, including human hepatoma BEL-7402, human breast cancer MCF-7 and human colon cancer HCT116 cells. However, no inhibitory effect was found when treating murine normal fibroblasts NIH3T3 and benign human breast MCF-10A cells with MML. The cell death induced by MML was characterized by cell morphological changes. The induction of apoptosis of BEL-7402 cells by MML was weak by DNA ladder assay. The possible mechanisms of its anti-tumor effect might be
\end{abstract}

Correspondence to: Dr Xiukun Lin, Institute of Oceanology, Chinese Academy of Sciences, 7 Nanhai Rd, Qingdao 266071, P.R. China

E-mail: linxiukun@yahoo.com

Abbreviations: VEGF, vascular endothelial growth factor; FCS, fetal calf serum; FPLC, fast protein liquid chromatography; BCA, bicinchoninic acid; BSA, bovine serum albumin; SDS, sodium dodecyl sulphate; MTT, 3-(4,5-di-methylthiazolzyl-2-yl)-2,5diphenyltetrazolium bromide; DMSO, dimethyl sulfoxide; SEM, scanning electron microscopy; PI, propidium iodide; LDH, lactate dehydrogenase; PBS, phosphate-buffered saline; PBS/FBS, PBS, $\mathrm{pH} 7.4$, containing $10 \%$ fetal bovine serum (FBS)

Key words: Meretrix meretrix Linnaeus, anti-tumor protein, cytotoxicity, cell membrane permeability, cell cycle, tubulin polymerization, apoptosis the changes in cell membrane permeability and inhibition of tubulin polymerization. MML may be developed as a novel, highly selective and effective anti-cancer drug.

\section{Introduction}

Marine organisms represent an essentially unexploited reservoir for discovery and development of potential products of genetic, biological and/or pharmacological interest, in particular for anti-cancer drugs (1-4). Some natural products derived from marine organisms are evaluated and developed in preclinical and/or clinical status as potential anti-cancer drugs and these kinds of products are dominated by lowmolecular-weight compounds so far (4). However, a few macromolecular compounds with anti-tumor activity have also been reported. For example, Aplysianins (5-7), Julianins $(8,9)$ and Dolabellanins $(10-13)$ are all glycoproteins isolated from different tissues of sea hare and they can inhibit the proliferation of multiple tumor cells and cause tumor lysis (5-13). Cyplasin is a $56 \mathrm{kDa}$ cytotoxic protein isolated from the mucus of European sea hare Aplysia punctata and it shows preferential toxicity to autonomously growing transformed mammalian cells (4). Previous study from our laboratory confirmed that a novel polypeptide PG155 from shark cartilage showed potent anti-angiogenic activity by inhibiting vascular migration and tubulogenesis of human umbilical vein endothelial cells induced by vascular endothelial growth factor (VEGF). Further study revealed that PG155 could significantly inhibit angiogenesis of zebrafish embryos in vivo (14).

Meretrix meretrix Linnaeus has long been used as traditional Chinese medicine for the treatment of various cancers and other diseases. There is evidence to show that $M$. meretrix has anti-cancer efficacy, eliminating cysts and detoxification (15-18). Several peptides and proteins with antitumor activity have also been extracted from $M$. meretrix. Leng et al purified a peptide from M. meretrix, which exhibited strongly inhibitory effect on the growth of human stomach adenocarcinoma BGC-823 cells (18). In addition, two glycoproteins, MGP0405 (MW: 9,655 Da) and MGP0501 (MW: $15,878 \mathrm{Da})$, were reported to have anti-tumor effect in vitro $(19,20)$. 
In the present studies, we extracted and purified a novel protein with potent anti-tumor activity from the coelomic fluid of $M$. meretrix. The effects of this protein on cell growth inhibition and morphological alterations were evaluated on several human cancer cell types. In order to find the possible mechanisms of the anti-tumor activity of MML, we investigated its effects on the changes of cell membrane permeability by SEM observation, Hoechst 33342/PI dual staining and LDH leakage assays. We also studied the effect of MML on the inhibition of tubulin polymerization by tubulin immunofluorescence staining. DNA ladder assay was employed to study apoptosis induced by MML in BEL-7402 cells.

\section{Materials and methods}

Materials, cell lines and cell culture. M. meretrix was purchased from the Fishery Company of Qingdao, China. The human hepatoma cell line BEL-7402 was provided by Cell Bank, Type Collection of Chinese Academy of Sci., China, while the other cells, including human breast cancer MCF-7, colon cancer HCT116 cells as well as murine fibroblasts NIH3T3 and human breast epithelial MCF-10A cells were obtained from American Type Culture Collection. Murine fibroblasts NIH3T3 cells were grown as monolayer in DMEM medium supplemented with $10 \%$ FCS, while other cell lines were cultured in RPMI-1640 medium. All cells were incubated at $37^{\circ} \mathrm{C}$ in a humidified air atmosphere containing $5 \% \mathrm{CO}_{2}$.

Procedures for extraction and purification. The fluids were collected from the cavity of $M$. meretrix by splitting the shells open and they were centrifuged at $8,000 \mathrm{x}$ g for $30 \mathrm{~min}$ to remove the precipitates. Ammonium sulphate powder was slowly added to the supernatants to reach a saturation of $40 \%$. After centrifugation at $12,000 \mathrm{x}$ g for $30 \mathrm{~min}$, the supernatants were collected and additional ammonium salt was added to reach $60 \%$ saturation. The precipitates were collected by centrifugation at $12,000 \times \mathrm{g}$ for $30 \mathrm{~min}$, dialyzed against $0.05 \mathrm{M}, \mathrm{pH} 6.0$ sodium acetate buffer, applied to a CMcellulose-52 column and eluted with the same buffer containing $0.08 \mathrm{M}, 0.3 \mathrm{M}$ and $1 \mathrm{M}$ sodium chloride.

All of the fractions were collected and analyzed their cytotoxicity by MTT assay. The active fractions were dialyzed against $0.05 \mathrm{M}$ sodium acetate buffer, $\mathrm{pH} 6.0$ containing $2.2 \mathrm{M}$ sodium chloride. Then the supernatants were loaded to a Phenyl Sepharose FF column. The column was washed with the starting buffer and eluted with $1 \mathrm{M}$ sodium chloride, $\mathrm{H}_{2} \mathrm{O}$ and 5\% ethylene glycol, respectively. The active fractions were pooled and dialyzed against $0.02 \mathrm{M}$ Tris buffer, $\mathrm{pH} 7.8$. The supernatants were applied to a REsource15Q column on FPLC (GE, USA). Elution was performed with the same buffer containing $0.1 \mathrm{M}$ and $0.5 \mathrm{M}$ sodium chloride. The protein concentrations of each fraction were determined by using the BCA protein assay kit (Pierce, USA).

SDS-polyacrylamide gel electrophoresis. SDS-polyacrylamide gel electrophoresis was performed to determine the purity of isolated proteins according to the method described by Laemmli (21). Purified protein $(0.1 \mu \mathrm{g})$ was used in the analysis. Electrophoresis of protein was carried out on $12 \%$ polyacrylamide gel stained with Coomassie brilliant blue R250.
Assessment of cytotoxicity. The inhibitory effects of the antitumor protein on the growth of cancer cells as well as benign cells NIH3T3 and MCF-10A were assessed in vitro by MTT assay (22). Five thousand cells per well were seeded in a 96well microplate. Cells were cultured in $180 \mu 1$ media of RPMI-1640 or DMEM for $24 \mathrm{~h}$. The purified protein with different concentrations was added to the medium. After $48 \mathrm{~h}$, MTT solution $(100 \mu 1,0.5 \mathrm{mg} / \mathrm{ml})$ was added into each well and the cells were incubated for another $4 \mathrm{~h}$. After adding $150 \mu \mathrm{l}$ DMSO to each aspirated well, the plate was gently agitated until the color reaction was uniform. The $\mathrm{OD}_{570}$ was determined by a microplate reader (Bio-Tek Instruments, USA) with subtraction of background absorbance.

Morphological alterations of BEL-7402 cells. Morphological alterations of BEL-7402 cells after MML treatment were investigated using phase contrast microscopy and SEM. The cells were seeded and cultured in 96-well plates, as described above. After incubation with 52.2 $\mu \mathrm{g} / \mathrm{ml} \mathrm{MML}$, the morphology of cells was observed under the CKX41 phase contrast microscopy (Olympus, Japan) and photographed at 30, 60, 90 and 120 min, respectively. In the SEM experiment, BEL-7402 cells were grown onto poly-L-lysine-coated coverslips in 6 -well plates for $24 \mathrm{~h}$ to allow firm attachment. Then they were treated with $52.2 \mu \mathrm{g} / \mathrm{ml} \mathrm{MML}$ and incubated for $60 \mathrm{~min}$. The medium containing MML was removed and subsequently the cells were fixed in glutaraldehyde. After fixation overnight at $4^{\circ} \mathrm{C}$, the coverlips were dehydrated in ethanol and dried in a critical point dryer. Cells on coverslips were coated with gold and analyzed by the S-3400N SEM (Hitachi, Japan).

Hoechst 33342/PI dual staining. The BEL-7402 cells were seeded in 6-well plates at $5 \times 10^{4}$ per well and treated with $52.2 \mu \mathrm{g} / \mathrm{ml}$ MML. After incubation for $24 \mathrm{~h}$, the cells were collected into a $1.5 \mathrm{ml}$ Eppendorf tube, centrifuged at $1,000 \mathrm{x} \mathrm{g}$ for $5 \mathrm{~min}$ to remove the medium and then stained with Hoechst 33342 and PI by using the dual staining Kit (Beyond, China). The cells were spread on slides and observed under the fluorescence microscopy (Zeiss, Germany).

LDH leakage assay. LDH leakage assay was performed to determine the membrane damage and loss of membrane integrity. The cells were seeded and cultured in 96-well plates, as described above. After incubation with various concentrations $(26.1,52.2,104.4 \mu \mathrm{g} / \mathrm{ml})$ of MML for $24 \mathrm{~h}$, the activity of LDH in the medium supernatants(S) and remaining cells $(\mathrm{C})$ was analyzed using the Colorimetric LDH cytotoxicity assay kit (Promega, USA). The percentage of LDH leakage was calculated as follows, leakage $(\%)=$ $\mathrm{S} /(\mathrm{S}+\mathrm{C}) \times 100 \%$.

Cell cycle analysis. BEL-7402 cells were seeded at $3 \times 10^{4} / \mathrm{cm}^{2}$ in $10-\mathrm{cm}$ dishes and treated with $52.2 \mu \mathrm{g} / \mathrm{ml} \mathrm{MML}$. After incubation for $24 \mathrm{~h}$, the cells were collected and washed with PBS for three times and then were resuspended in $5 \mu \mathrm{g} / \mathrm{ml} \mathrm{PI}(1 \mathrm{ml})$ containing $100 \mathrm{U} / \mathrm{ml}$ RNase A. The DNAs of cells were stained by PI, while the RNAs were removed by digestion with RNase $\mathrm{A}$ at $4^{\circ} \mathrm{C}$ for $30 \mathrm{~min}$. The DNA contents of the cells were determined by FACSCalibur ${ }^{\mathrm{TM}}$ cytometer (Becton-Dickinson, Germany). 

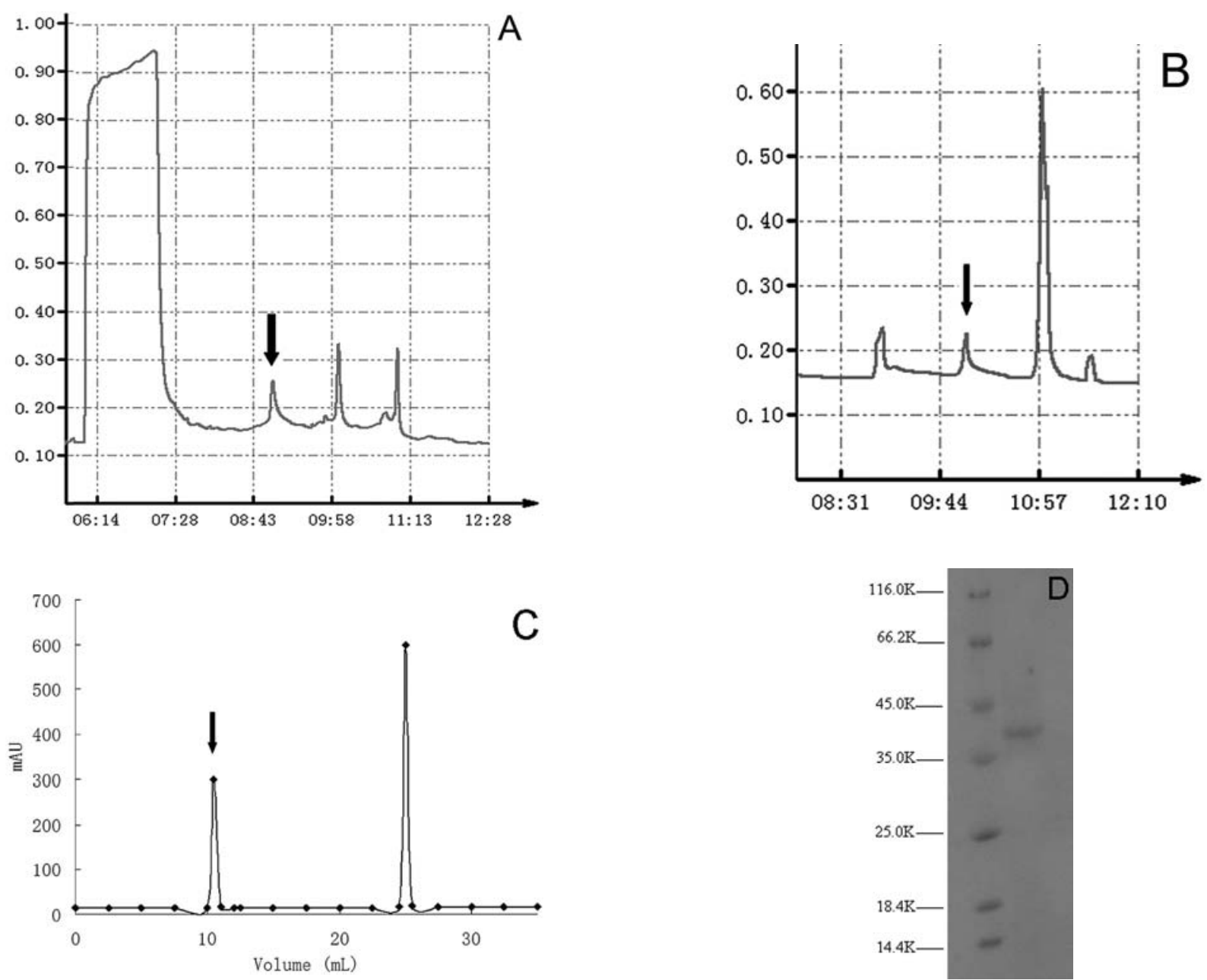

Figure 1. Elution patterns on column chromatography and SDS-PAGE analysis of MML. The arrow indicated the active component during the purification. (A) The dialyzed ammonium sulphate fraction was applied to a CM-cellulose-52 column equilibrated with $0.05 \mathrm{M}$, $\mathrm{pH} 6.0$ sodium acetate buffer and was eluted with the same buffer containing $0.08,0.3$ and $1 \mathrm{M}$ sodium chloride. The eluted active fraction was applied to Phenyl Sepharose FF column equilibrated with $0.05 \mathrm{M}$, pH 6.0 sodium acetate containing $2.2 \mathrm{M}$ sodium chloride and was eluted with $1 \mathrm{M}$ sodium chloride, water and $5 \%$ ethylene glycol (B). The active fraction from phenyl sepharose chromatography was applied to a REsource-15Q column equilibrated with $0.02 \mathrm{M}$ Tris buffer, $\mathrm{pH} 7.8$ and was eluted with the same buffer containing 0.1 and $0.5 \mathrm{M}$ sodium chloride (C). SDS-PAGE analysis of the purified MML from the coelomic fluid of M. meretrix (D). The purified MML was resolved on 12\% polyacrylamide gel and the gel was stained with Coomassie brilliant blue R250.

Indirect immunofluorescence detection of $\alpha$-tubulin. BEL-7402 cells were grown onto glass coverslips in 6-well dishes. After incubation for $24 \mathrm{~h}$, the cells were exposed to $52.2 \mu \mathrm{g} / \mathrm{ml}$ MML for $30 \mathrm{~min}$. Then the cells were fixed with $2 \%$ paraformaldehyde for $10 \mathrm{~min}$ at room temperature. After washing twice with PBS, the cells were blocked with PBS/FBS solution for $20 \mathrm{~min}$ and then incubated with mouse monoclonal anti$\alpha$-tubulin antibody (1:500, Calbiochem, USA) in 0.1\% Triton/ $\mathrm{PBS} / \mathrm{FBS}$ solution for $60 \mathrm{~min}$ at room temperature in a humidified chamber. After washing twice with PBS/FBS solution, the cells were incubated with a second antibody (FITC-anti-mouse IgG, 1:500, Calbiochem) in the dark for $60 \mathrm{~min}$ at room temperature, washed again with $\mathrm{PBS} / \mathrm{FBS}$ solution and covered with a glass slide. Cellular microtubules were observed under fluorescence microscopy (Zeiss, Germany).

DNA ladder assay. BEL-7402 cells were seeded at $3 \times 10^{4} / \mathrm{cm}^{2}$ in $10-\mathrm{cm}$ dishes and incubated for $24 \mathrm{~h}$. After treated with $52.2 \mu \mathrm{g} / \mathrm{ml} \mathrm{MML}$ for $48 \mathrm{~h}$, the cells were collected and total genomic DNA was extracted according to the protocol described in Universal Genomic DNA extraction kit (Takara, Japan). The DNA samples were resolved on $1.0 \%$ agarose gel stained with $0.5 \mu \mathrm{g} / \mathrm{ml}$ of ethidium bromide and photographed by Quantity one system (Bio-Rad, USA).

\section{Results}

Extraction and purification of the protein from Meretrix meretrix. The protein was extracted and purified from the coelomic fluid by ammonium sulphate fractionation, ion exchange and hydrophobic interaction chromatography. The elution profiles on column chromatography are shown in Fig. 1. The precipitates formed at 40-60\% ammonium sulphate saturation were applied to a CM-cellulose-52 column. The active fractions were eluted with $0.08 \mathrm{M}$ sodium chloride solution (Fig. 1A) and further purified by Phenyl Sepharose FF (Fig. 1B). After hydrophobic chromatography, the active components were applied to a REsource-15Q pre-packed column eluted with $0.1 \mathrm{M}$ sodium chloride solution, and 


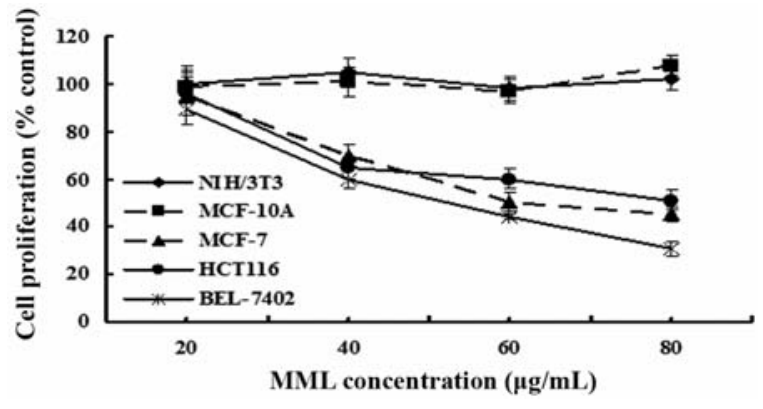

Figure 2. MML inhibited the growth of several types of cancer cells. Human hepatoma BEL-7402 (star), human colon cancer HCT116 (solid circle), human breast cancer MCF-7 (triangle), human breast epithelial cell MCF10A (solid box) and murine fibroblast NIH3T3 cells (diamond) were incubated in the absence or presence of various concentrations of MML for $48 \mathrm{~h}$ at $37^{\circ} \mathrm{C}$. MTT assay was performed to determine the growth inhibition of different cancer cells and benign NIH3T3 and MCF-10A cells by MML. The experiments were performed more than three times and the results were compared to untreated cells. purified to homogeneity (Fig. 1C). The purified protein, designated MML, revealed as a single band of $40 \mathrm{kDa}$ on SDS-polyacrylamide gel electrophoresis (Fig. 1D).

Cytotoxicity of MML against human cancer cells. During the purification process, MTT colorimetric method was employed to trace the active components for cell growth inhibition against human hepatoma BEL-7402 cells. The purified protein, MML, significantly inhibited the growth of BEL-7402 cells and the $\mathrm{IC}_{50}$ was determined to be $52.2 \mu \mathrm{g} / \mathrm{ml}$ (Fig. 2). MML displayed cytotoxicity also to human breast cancer MCF-7 and human colon cancer HCT116 cells. However, it had no inhibitory effect on the growth of benign cells, including murine fibroblasts NIH3T3 as well as human breast epithelial cell line MCF-10A at a concentration of $80 \mu \mathrm{g} / \mathrm{ml}$ (Fig. 2). Moreover, no growth inhibition of NIH3T3 and MCF-10A cells was found while increasing the concentration of MML to $300 \mu \mathrm{g} / \mathrm{ml}$ (data not shown).
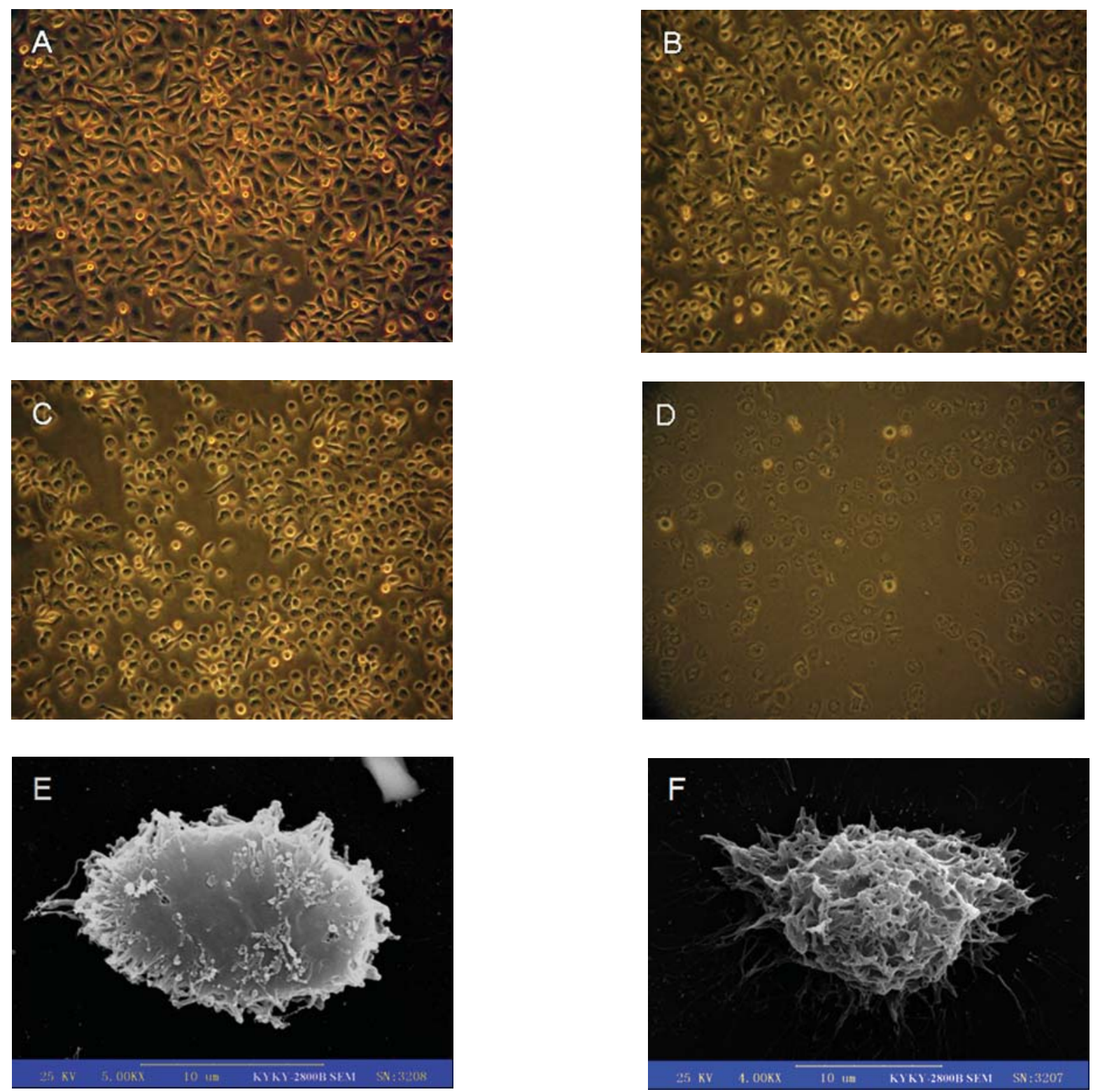

Figure 3. Morphological analysis of BEL-7402 cells induced by MML. The cells were untreated (Panel A) or treated with $52.2 \mu \mathrm{g} / \mathrm{ml} \mathrm{MML} \mathrm{for} 30 \mathrm{~min}$ (Panel B), $60 \mathrm{~min}$ (Panel C), and $90 \mathrm{~min}$ (Panel D). In the SEM experiment, BEL-7402 cells were grown onto poly-L-lysine-coated coverslips for $24 \mathrm{~h}$ to allow firm attachment and treated with $52.2 \mu \mathrm{g} / \mathrm{ml}$ MML for $60 \mathrm{~min}$. Cells were fixed on coverslips coated with gold and analyzed by using the S-3400N SEM. Panel E represented the results of untreated cells and Panel F displayed the results of cells treated with MML (Scale bar $=10 \mu \mathrm{m}$ ). 

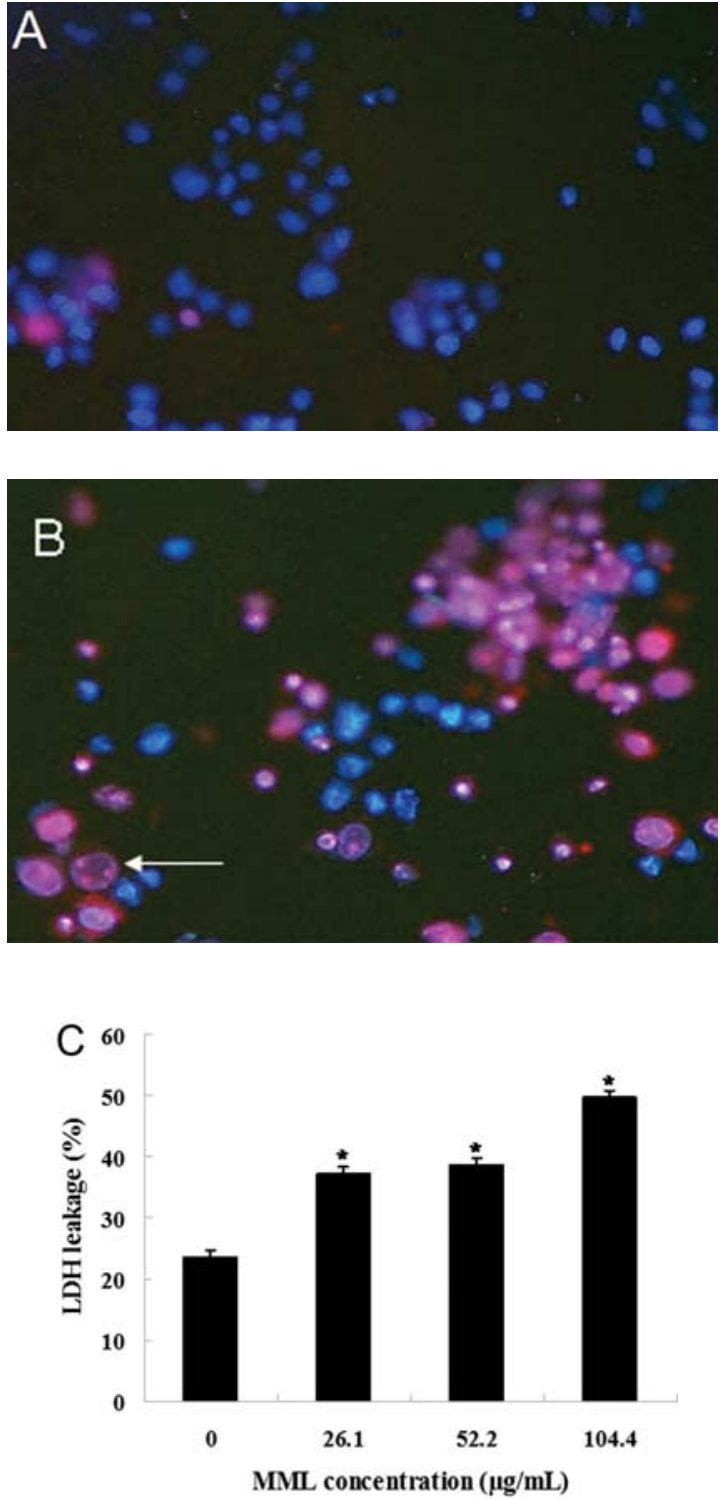

Figure 4. MML increased cell membrane permeability as determined by Hoechst 33342/PI staining and LDH leakage assay. After incubation for $24 \mathrm{~h}$, the cells were collected stained with Hoechst 33342 and PI and then the cells were spread on glass slides and observed under the fluorescence microscopy. For the untreated cells, only Hoechst 33342 staining was found (A). In contrast, the cells treated with MML were stained by both Hoechst 33342 and PI (arrows, B). For LDH leakage assay, cells were incubated with various concentrations $(26.1,52.2$ and $104.4 \mu \mathrm{g} / \mathrm{ml})$ of $\mathrm{MML}$ for $24 \mathrm{~h}$ at $37^{\circ} \mathrm{C}$. The percentage of LDH leakage (C) was analyzed, as described in Materials and methods. The asterisk indicates the significant difference between the group of untreated control and the groups of MML treatment $(\mathrm{P}<0.01)$

MML induces the morphological alterations of BEL-7402 cells. Remarkable alterations of cell membrane of BEL-7402 cells were observed after MML treatment. The architecture of untreated BEL-7402 cells displayed a typical spindle shape (Fig. 3A). However, the morphology of the cells started to change in a short time after incubation with MML. The cells detached from the substratum, became rounding (Fig. 3B) and separated from each other (Fig. 3C) after exposure to MML for 30-60 min. Membrane bulge and detachment from cytoplasmic inclusion were observed in $90 \mathrm{~min}$ after MML treatment (Fig. 3D). Obvious bulging of the membranes was found when treated with MML for 120 min (data not shown).
The morphologic changes of the cell membrane were also clearly visualized by SEM. The untreated BEL-7402 cells showed a normal smooth surface (Fig. 3E). In contrast, the cells treated with MML became rounded and the surface of the cell membrane was markedly disrupted (Fig. 3F).

$M M L$ increases the permeability of cell membrane of BEL7402 cells. To demonstrate the effects of MML on cell permeability of BEL-7402 cells, Hoechst 33342/PI dual staining and LDH leakage assay were performed. The BEL-7402 cells displayed integrate cell membranes and did not stain by PI without MML treatment (Fig. 4A). In contrast, typical red fluorescence of PI in the BEL-7402 cells was visible after MML treatment (Fig. 4B). The results demonstrated that MML increased the membrane permeability of BEL-7402 cells. Furthermore, the percentage of LDH leakage was significantly increased $(\mathrm{P}<0.01)$ in BEL-7402 cells treated with MML compared to that of untreated cells (Fig. 4C). The increase of LDH activity was in a dose-dependent manner and more LDH leakage was observed with higher MML concentrations (Fig. 4C).

MML induces cell cycle arrest in G2/M phase and inhibits tubulin polymerization. To further evaluate the mode of action of MML, the effects of MML on the location of BEL-7402 cells in the cell cycle were examined by using flow cytometry analysis. The result showed that MML blocked BEL-7402 cells in G2/M phase in a dose-dependent manner (Fig. 5). Since microtubule-targeted anti-cancer agents arrested cell cycle in $\mathrm{G} 2 / \mathrm{M}$ phase, we examined the microtubule network of BEL-7402 cells treated with MML by indirect immuno-fluorescence approach. The result of MML affecting tubulin polymerization is shown in Fig. 6. The microtubule network in untreated cells showed normal organization (Fig. 6A) while tubulin polymerization was inhibited in treated cells (Fig. 6B).

DNA ladder assay. To further understand the molecular events underlining the MML on cancer cells, DNA ladder assay was performed to study MML inducing apoptosis. As shown in Fig. 7, BEL-7402 cells treated with VP16 (positive control) were characterized by fragmentation of DNA (DNA ladder) on the agarose gel. Electrophoresis of DNA from the cells treated with MML also displayed DNA ladders, but the fragmentation was much weaker than that of the VP16-treated cells.

\section{Discussion}

In the present study, we extracted and purified a novel antitumor protein from the coelomic fluid of Meretrix meretrix Linnaeus. MTT assay indicated that purified MML could selectively inhibit the proliferation of several human cancer cells. Treatment of human hepatoma BEL-7402 cells with MML resulted in increased permeability of cell membrane and inhibition of tubulin polymerization.

An interesting point in our study was that the novel protein, MML, displayed potent cytotoxicity to human hepatoma BEL-7402 cells. Also, MML could inhibit the growth of human breast cancer MCF-7 and human colon cancer HCT116 

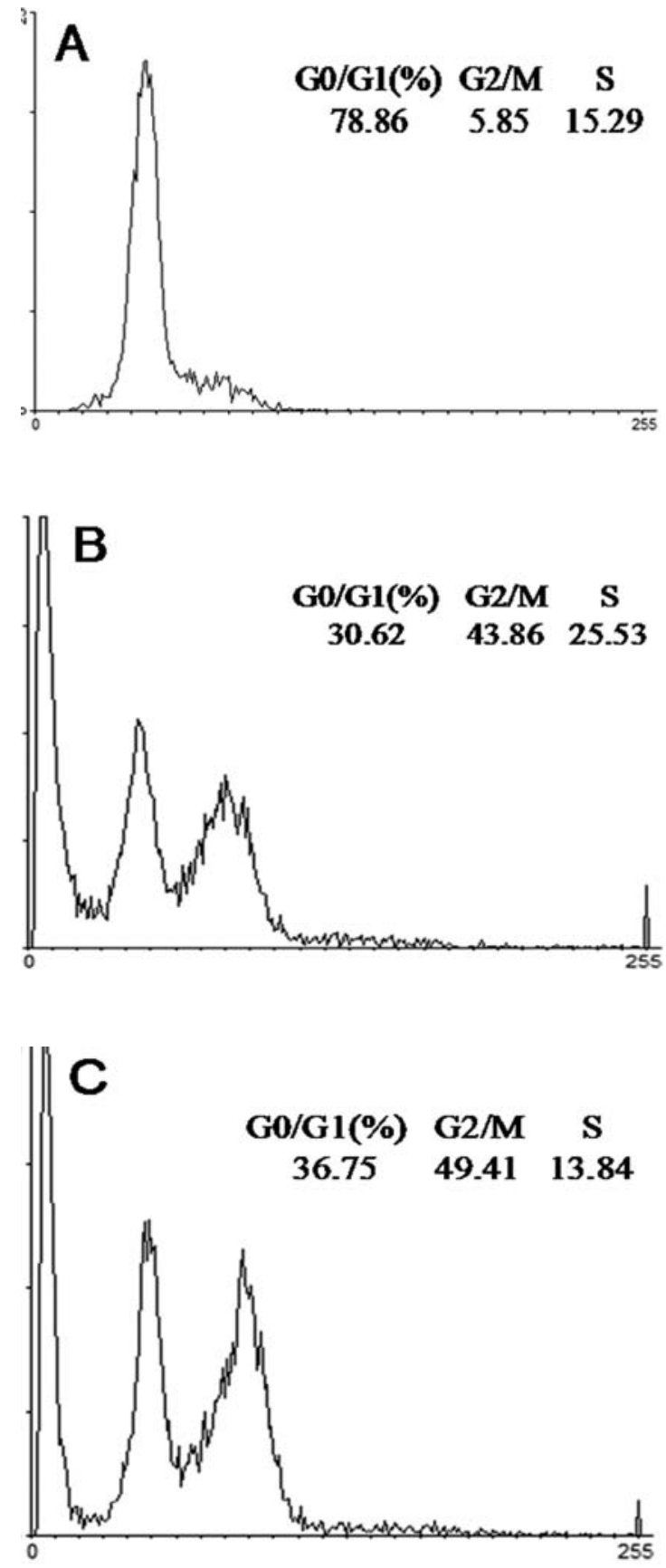

Figure 5. Effect of MML on cell cycle distribution. BEL-7402 cells were seeded at $3 \times 10^{4} / \mathrm{cm}^{2}$ in $10-\mathrm{cm}$ dishes with or without MML treatment. After $24 \mathrm{~h}$ incubation, the untreated cells (A) and the cells treated with MML at $52.2 \mu \mathrm{g} / \mathrm{ml}$ (B), or $104.4 \mu \mathrm{g} / \mathrm{ml}$ (C) were collected and the DNAs were stained by PI, while the RNAs were removed by digestion with RNase A. The DNA contents of the cells were determined with FACSCalibur ${ }^{\mathrm{TM}}$ cytometer.

cells significantly. However, no inhibition effect was found when treating murine fibroblast NIH3T3 cells and human benign breast MCF-10A cells with MML. These results demonstrated that MML could selectively inhibit tumor cells. Previous studies show that many anti-microbial peptides, such as insect cecropins (23) and magainins (24-26), exhibit antitumor effects in vitro and/or in vivo. Some of them are proved to have selective activity on different tumor cells. Magainin II displayed significant anti-tumor activities against various cancer cell lines in vitro and animal tumor models in vivo, but did not display cytotoxicity to the fibroblasts NIH3T3 cells
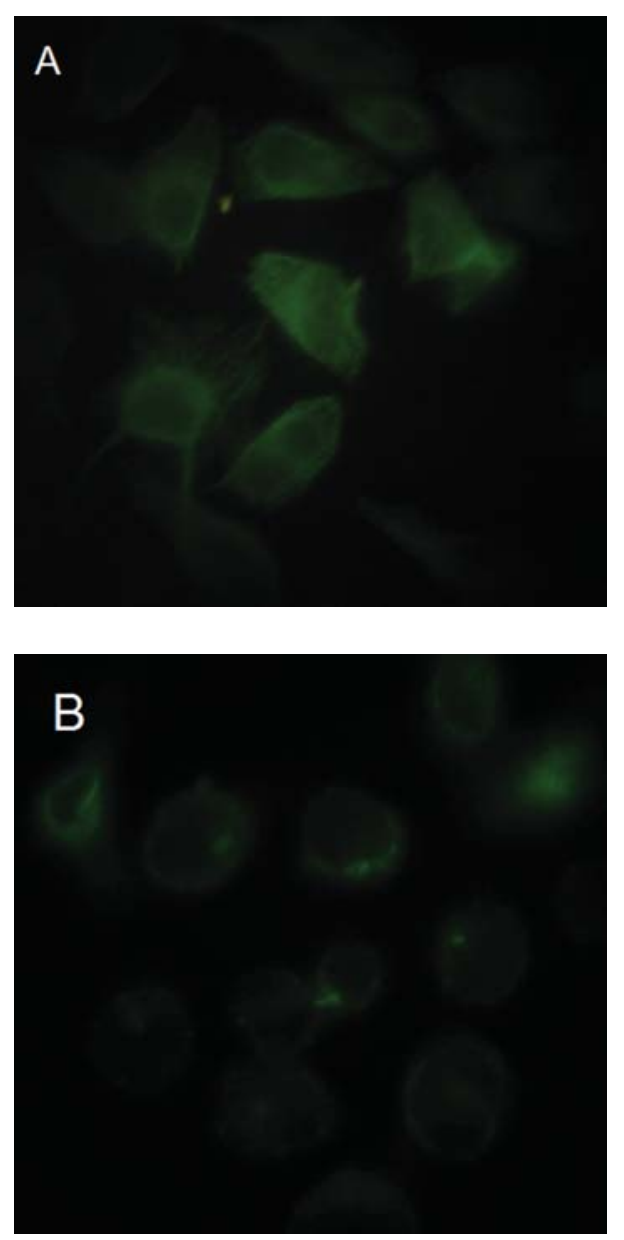

Figure 6. MML inhibits polymerization of cellular $\alpha$-tubulin. BEL-7402 cells were grown onto glass coverslips placed in petri dishes. After incubation for $24 \mathrm{~h}$, the untreated cells (A) and the cells treated with $52.2 \mu \mathrm{g} / \mathrm{ml}$ MML (B) were fixed in $2 \%$ paraformaldehyde for $10 \mathrm{~min}$ at room temperature. After washing twice with PBS, the cells were incubated with mouse monoclonal anti- $\alpha$-tubulin antibody (1:500) for $60 \mathrm{~min}$. After washing twice with PBS/FBS solution, cells were incubated with a second antibody (FITC-antimouse IgG, 1:500) and covered with a glass slide. Cellular microtubules were observed under fluorescence microscopy.

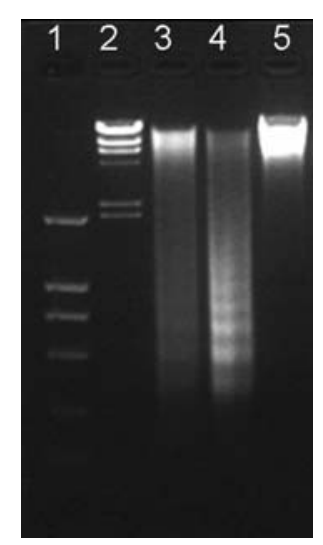

Figure 7. Effect of MML on apoptosis of BEL-7402 cells. The cells were seeded at $3 \times 10^{4} / \mathrm{cm}^{2}$ in $10-\mathrm{cm}$ dishes and incubated for $24 \mathrm{~h}$. The untreated cells and the cells treated with $52.2 \mu \mathrm{g} / \mathrm{ml}$ MML or $5 \mu \mathrm{M}$ VP16 were incubated for another $48 \mathrm{~h}$. The cells were collected and total DNA was extracted and analyzed by electrophoresis on $1.0 \%$ agarose gel. Lane 1 and lane 2 represents DNA marker. Lane 3 indicates the cells treated with MML. Lane 4 indicates the cells treated with VP16. The untreated cells are indicated in lane 5 . 
(27). It was found that magainin II could interact strongly with the anionic lipid of cell membranes (28). However, further study is needed to address if there are differences in the contents of anionic lipid between tumor and benign cells.

There is evidence to show that most of anti-microbial peptides cause cell death by increasing cell membrane permeability. Cecropin A and B, anti-microbial peptides isolated from the hemolymph of giant silk moth Hyalophora cecropia (29), possessed the ability to form specific amphipathic $\alpha$-helices to target non-polar lipid cell membranes (30-32). The peptides targeted membrane by forming ionpermeable channels and subsequently resulted in cell depolarization, irreversible cytolysis and finally cell death $(33,34)$. Previous studies have demonstrated that both Cecropin A and B family members showed cytolytic activity against various human cancer cell lines, including leukemia, lymphoma and colon carcinoma $(23,35)$ as well as small cell lung cancer (36), gastric cancer (37) and bladder cancer (38). Intensive studies have proved that many anti-microbial peptides utilized a unique mechanism to lyse the membrane of cancer cells, either in a 'carpet' model (39-42) or in a 'barrel-stave' model $(40,43,44)$. Compared with these anti-microbial peptides, MML displayed similar effects against human hepatoma BEL-7402 cells. However, since MML is a macromolecular protein, further studies are required to elucidate the action mode of MML on cancer cell membranes.

Microtubules are the major dynamic structural components in cells and used as the target by several classes of anti-cancer agents. Previous studies with mitotic inhibitors from marine organisms are dominated by the compounds of low-molecularweight. Dolastatin 10, an anti-cancer peptide isolated from the sea hare, could block cells in G2/M phase by inhibiting tubulin polymerization (45-48). Our results suggested that MML, likes Dolastatin 10, also induced cell arrest in G2/M phase and the effect might attribute to its inhibition effect on tubulin polymerization. A number of anti-cancer agents could inhibit the tubulin polymerization by direct interaction with tubulin. For example, cryptophycin, vinorelbine and colchicines could bind directly with different sites on tubulin molecule and affect the tubulin polymerization (49-51). Further studies are ongoing in our laboratory to investigate if MML interacts with tubulin directly or through receptormediated signal transduction events.

Most anti-cancer agents induce cell death by apoptosis and nuclear fragmentation was a typical indicator for cell apoptosis $(52,53)$. In the present study, obvious DNA ladder was observed in the hepatoma cells treated with VP16, while only much weaker DNA fragmentation was presented in the MML-treated cells. Based on this finding, the induction of apoptosis might not be the main effect of MML for its cytotoxicity to human hepatoma cells.

In summary, MML is a novel protein isolated from a marine mollusk with remarkable in vitro anti-tumor activity against cancer cells. MML selectively inhibited the growth of several types of cancer cells. The inhibitory effect of MML on the proliferation of human hepatoma BEL-7402 cells appeared to involve increased cell membrane permeability and damage and inhibition of microtubules polymerization. However, the interaction of this protein with cell membrane and tubulin and the interacting sites on tubulin molecules still require to be further investigated. MML may be a good candidate to be developed as a novel and effective anticancer drug.

\section{Acknowledgements}

The authors were grateful to Shousong Cao at the Roswell Park Cancer Institute for his careful review of the study and also grateful to Mr. Hao Jiang and all members of the laboratory for their continuous technical advice and helpful discussion. This study was supported by 863 High Technology Project (No\# 2007AA091403 and 2007AA09Z408) from the Chinese Ministry of Science and Technology and supported in part by the innovative projects of Chinese Academy of Sciences (No\# KSCX2-YW-104 and KZCX2-YW-209).

\section{References}

1. de Vries DJ and Beart PM: Fishing for drugs from the sea: status and strategies. Trends Pharmacol Sci 16: 275-279, 1995.

2. Wallace RW: Drugs from the sea: harvesting the results of aeons of chemical evolution. Mol Med Today 3: 291-295, 1997.

3. Fenical W: New pharmaceuticals from marine organisms. Trends Biotechnol 15: 339-341, 1997.

4. Petzelt C, Joswig G, Stammer H and Werner D: Cytotoxic Cyplasin of the sea hare, Aplysia punctata, cDNA cloning, and expression of bioactive recombinants in insect cells. Neoplasia 4: 49-59, 2002.

5. Kisugi J, Kamiya $\mathrm{H}$ and Yamazaki M: Purification and characterization of aplysianin E, an antitumor factor from sea hare eggs. Cancer Res 47: 5649-5653, 1987.

6. Yamazaki M, Kimura K, Kisugi J, Muramoto K and Kamiya H: Isolation and characterization of a novel cytolytic factor in purple fluid of the sea hare, Aplysia kurodai. Cancer Res 49: 3834-3838, 1989.

7. Kamiya H, Muramoto K and Yamazaki M: Aplysianin A, an antibacterial and antineoplastic glycoprotein in the albumen gland of a sea hare, Aplysia kurodai. Experientia 42: 1065-1067, 1986.

8. Kamiya H, Muramoto K, Goto R, Sakai M, Endo Y and Yamazaki M: Purification and characterization of an antibacterial and antineoplastic protein secretion of a sea hare, Aplysia Juliana. Toxicon 27: 1269-1277, 1989

9. Kamiya H, Muramoto K, Goto $\mathrm{R}$ and Yamazaki M: Characterization of an antibacterial and antineoplastic glycoprotein in a sea hare, Aplysia Juliana. Nippon Suisan Gakkaishi 54: 773-777, 1989.

10. Yamazaki M, Tansho S, Kisugi J, Muramoto K and Kamiya H: Purification and characterization of a cytolytic protein from purple fluid of the sea hare, Dolabella auricularia. Chem Pharm Bull 37: 2179-2182, 1989.

11. Kisugi J, Yamazaki M, Tansho S, Muramoto K and Kamiya H: Purification of a novel cytolytic protein from albumen gland of the sea hare, Dolabella auricularia. Chem Pharm Bull 37: 2773-2781, 1989.

12. Kisugi J, Kamiya $\mathrm{H}$ and Yamazaki M: Purification of dolabellanin-C, an antineoplastic glycoprotein in the body fluid of a sea hare, Dolabella auricularia. Dev Comp Immunol 13: 3-15, 1989

13. Yamazaki M: Antitumor and antimicrobial glycoproteins from sea hares. Comp Biochem Physiol 105C: 141-146, 1993.

14. Zheng LH, Ling PX, Wang Zh, Niu RL, Hu ChX, Zhang TM and Lin XK: A novel polypeptide from shark cartilage with potent anti-angiogenic activity. Cancer Biol Ther 6: 775-780, 2007.

15. Chen HY, Cong XQ, Zhang A and Zhu JM: The anticancer research of extraction from Mercenaria. Cancer Res Prev Treat (in Chinese) 4: 3-7, 1980.

16. Zhang JX and Xing YP: Studies on anti-cancer activity of Meretrix Meretrix nucleic acid. Oceanol Et Limnol (in Chinese) 21: 88-91, 1990.

17. Dou CH, Huang F, Huang LS, Li PZ and Xiao WD: An experimental study on the effects of Meretrix polysaccharide. J Marine Drugs (in Chinese) 2: 15-19, 1999. 
18. Leng B, Liu XD and Chen QX: Inhibitory effects of anticancer peptide from Mercenaria on the BGC-823 cells and several enzymes. FEBS Lett 579: 1187-1190, 2005.

19. Zhang B and Wu JL: Isolation and characterization of glycopeptide MGP0405 from Meretrix meretrix. Chin J Nat Med (in Chinese) 4: 230-233, 2006.

20. Wu JL, Zhang B, Huang CH, Zhu XC and Wu WT: The antitumor activity of glycopeptide (MGP0501) from Meretrix meretrix in vitro. Pharm Biotech (in Chinese) 13: 260-264, 2006.

21. Laemmli UK: Cleavage of structural proteins during the assembly of the bacteriophage T4. Nature 227: 680-688, 1970.

22. He QJ, Yang B, Lou YJ and Fang RY: Contragestazol (DL111-IT) inhibits proliferation of human androgen-independent prostate cancer cell line PC3 in vitro and in vivo. Asian J Androl 7: 389-393, 2005

23. Chen HM, Wang W, Smith D and Chan SC: Effects of the antibacterial peptide cecropin B and its analogs, cecropinsB-1 and B-2, on liposomes, bacteria and cancer cells. Biochim Biophys Acta 1336: 171-179, 1997.

24. Zasloff M: Magainins, a class of antimicrobial peptides from Xenopus skin: isolation, characterization of two active forms and partial cDNA sequence of a precursor. Proc Natl Acad Sci USA 84: 5449-5453, 1987.

25. Baker MA, Maloy WL, Zasloff M and Jacob LS: Anticancer efficacy of Magainin2 and analogue peptides. Cancer Res 53: 3052-3057, 1993.

26. Cruciani RA, Barker JL, Zasloff M, Chen HC and Colamonici O: Antibiotic magainins exert cytolytic activity against transformed cell lines through channel formation. Proc Natl Acad Sci USA 88: 3792-3796, 1991.

27. Lehmann J, Retz M, Sidhu SS, Suttmann H, Sell M, Paulsen F, Harder J, Unteregger G and Stockle M: Antitumor activity of the antimicrobial peptide Magainin II against bladder cancer cell lines. Eur Urol 50: 141-147, 2006.

28. Lad MD, Birembaut F, Clifton LA, Frazier RA, Webster JR and Green RJ: Antimicrobial peptide-lipid binding interactions and binding selectivity. Biophys J 92: 3575-3586, 2007.

29. Steiner H, Hultmark D, Engström A, Bennich H and Boman HG: Sequence and specificity of two antibacterial proteins involved in insect immunity. Nature 292: 246-248, 1981.

30. Steiner H, Andreu D and Merrifield RB: Binding and action of cecropin and cecropin analogues: antibacterial peptides from insects. Biochim Biophys Acta 939: 60-66, 1988.

31. Holak TA, Engström A, Kraulis PJ, Lindeberg G, Bennich H, Jones TA, Gronenborn AM and Clore GM: The solution conformation of the antibacterial peptide cecropin A: a nuclear magnetic resonance and dynamical simulated annealing study. Biochemistry 27: 7620-7629, 1988.

32. Christensen B, Fink J, Merrifield RB and Mauzerall D: Channel-forming properties of cecropins and related model compounds incorporated into planar lipid membranes. Proc Nat Acad Sci USA 85: 5072-5076, 1988.

33. Bechinger B: Structure and functions of channel-forming peptides: magainins, cecropins, melittin and alamethicin. J Membr Biol 156: 197-211, 1997.

34. Boman HG: Antibacterial peptides: basic facts and emerging concepts. J Intern Med 254: 197-215, 2003.

35. Moore AJ, Devine DA and Bibby MC: Preliminary experimental anticancer activity of cecropins. Pept Res 7: 265-269, 1994.
36. Shin SY, Lee MK, Kim KL and Hahm KS: Structure-antitumor and hemolytic activity relationships of synthetic peptides derived from cecropin A-magainin 2 and cecropin A-melittin hybrid peptides. J Pept Res 50: 279-285, 1997.

37. Chan SC, Hui L and Chen HM: Enhancement of the cytolytic effect of anti-bacterial cecropin by the microvilli of cancer cells. Anticancer Res 18: 4467-4474, 1998.

38. Suttmann H, Retz M, Paulsen F, Harder J, Zwergel U, Kamradt J, Wullich B, Unteregger G, Stöckle M and Lehmann J: Antimicrobial peptides of the Cecropin-family show potent antitumor activity against bladder cancer cells. BMC Urol 8: 5-11, 2008.

39. Shai Y: Mechanism of the binding, insertion and destabilization of phospholipid bilayer membranes by alpha-helical antimicrobial and cell non-selective membrane-lytic peptides. Biochim Biophys Acta 1462: 55-70, 1999.

40. Papo $\mathrm{N}$ and Shai $\mathrm{Y}$ : Host defense peptides as new weapons in cancer treatment. Cell Mol Life Sci 62: 784-790, 2005.

41. Matsuzaki K, Murase O and Miyajima K: Kinetics of pore formation by an antimicrobial peptide, magainin 2, in phospholipid bilayers. Biochemistry 34: 12553-12559, 1995.

42. Ludtke SJ, He K, Heller WT, Harroun TA, Yang L and Huang HW: Membrane pores induced by magainin. Biochemistry 35: 13723-13728, 1996.

43. Ehrenstein G and Lecar H: Electrically gated ionic channels in lipid bilayers. Q Rev Biophys 10: 1-34, 1977.

44. Vogel H, Jahnig F, Hoffmann V and Stumpel J: The orientation of melittin in lipid membranes: a polarized infrared spectroscopy study. Biochim Biophys Acta 733: 201-209, 1983.

45. Jordan MA: Mechanism of action of antitumor drug that interact with microtubules and tubulin. Curr Med Chem Anticancer Agents 2: 1-17, 2002.

46. Li Y, Kobayaski H, Hashimoto Y, Shirai R, Hirata A, Hayashi K, Hamada Y, Shiori T and Iwasaki S: Interaction of the marine toxin dolastatin 10 with porcine brain tubulin: competitive inhibition of rhizoxin and phomopsin A binding. Chem Biol Interact 93: 175-183, 1994.

47. Bai R, Taylor GF, Schmidt JM, Williams MD, Kepler JA, Pettit GR and Hamel E: Interaction of dolastatin 10 with tubulin: induction of aggregation and binding and dissociation reactions. Mol Pharmacol 47: 965-976, 1995.

48. Turner T, Jackson WH, Pettit GR, Wells A and Kraft AS: Treatment of human prostate cancer cells with Dolastatin 10, a peptide isolated from a marine shell-less mollusk. Prostate 34: 175-181, 1998 .

49. Smith CD and Zhang XQ: Mechanism of action of cryptophycin. J Biol Chem 271: 6192-6198, 1996.

50. Sorensen JB: Current position of vinorelbine in cancer chemotherapy. Ann Oncol 6: 105-107, 1995.

51. Bhattacharyya B, Panda D, Gupta S and Banerjee M: Anti-mitotic activity of colchicine and the structural basis for its interaction with tubulin. Med Res Rev 28: 155-183, 2008.

52. Arends MJ, Morris RG and Wyllie AH: Apoptosis: the role of the endonuclease. Am J Pathol 136: 593-608, 1990.

53. Compton MM: A biochemical hallmark of apoptosis: internucleosomal degradation of the genome. Cancer Metastasis Rev 11: 105-119, 1992. 